\title{
TrkB is highly expressed in NSCLC and mediates BDNF-induced the activation of Pyk2 signaling and the invasion of A549 cells
}

\author{
Siyang Zhang ${ }^{1}$, Dawei Guo², Wenting Luo ${ }^{3}$, Qingfu Zhang ${ }^{3}$, Ying Zhang ${ }^{1}$, Chunyan Li ${ }^{1}$, Yao Lu', Zeshi Cui ${ }^{1 *}$, \\ Xueshan Qiu ${ }^{3^{*}}$
}

\begin{abstract}
Background: Aberrant regulation in the invasion of cancer cells is closely associated with their metastatic potentials. TrkB functions as a receptor tyrosine kinase and is considered to facilitate tumor metastasis. Pyk2 is a non-receptor tyrosine kinase and integrates signals in cell invasion. However, little is known about the expression of TrkB in NSCLC and whether Pyk2 is involved in TrkB-mediated invasion of A549 cells.

Methods: The expression of TrkB was investigated in NSCLC by immunohistochemical staining. Both HBE and A549 cells were treated with BDNF. The expression of TrkB, Pyk2 and ERK phosphorylations were assessed by western blot. Besides, A549 cells were transfected with TrkB-siRNA or Pyk2-siRNA, or treated with ERK inhibitor where indicated. Transwell assay was performed to evaluate cell invasion.
\end{abstract}

Results: 40 cases (66.7\%) of NSCLC were found higher expression of TrkB and patients with more TrkB expression had significant metastatic lymph nodes $(p=0.028$ ). BDNF facilitated the invasion of A549 cells and the activations of Pyk2 in Tyr402 and ERK. However, the effects of BDNF were not observed in HBE cells with lower expression of TrkB. In addition, the increased Pyk2 and ERK activities induced by BDNF were significantly inhibited by blocking TrkB expression, so was the invasion of A549 cells. Knockdown studies revealed the essential role of Pyk2 for BDNFinduced cell invasion, since the invasion of A549 cells was abolished by Pyk2-siRNA. The application of ERK inhibitor also showed the suppressed ERK phosphorylation and cell invasion.

Conclusion: These data indicated that higher expression of TrkB in NSCLC was closely correlated with lymph node metastasis, and BDNF probably via TrkB/Pyk2/ERK promoted the invasion of A549 cells.

\section{Background}

Lung cancer is the leading cause of death among the malignant tumors worldwide, and the incidence of nonsmall cell lung cancer (NSCLC) is increasing. The prognosis of patients with NSCLC principally correlates with tumor metastasis, which involves the regulation of some critical genes and more information should be gathered on the research of those prometastatic genes.

Tropomysin-related kinase $B(\operatorname{Trk} B)$ is a member of Trk family, functions as a receptor tyrosine kinase. Brain-derived neurotrophic factor (BDNF), the primary

\footnotetext{
* Correspondence: labczs@mail.cmu.edu.cn; qiuxueshan_pathology@126.com 'Center of Laboratory Technology and Experimental Medicine, China Medical University, Shenyang, China

${ }^{3}$ Department of Pathology, the First Affiliated Hospital and College of Basic Medical Sciences of China Medical University, Shenyang, China
}

ligand, binding to TrkB results in the regulation of various cellular activities in neuroblastoma, such as cell differentiation [1], apoptosis [2], and invasion [3]. TrkB is up-regulated in a variety of primary human tumors, including neuroblastoma [4] and ovarian cancer [5], especially in metastatic gastric [6] and pancreatic tumors [7]. Enhanced TrkB signaling promotes cell survival in an anchorage-independent manner [8]. When activated by BDNF, TrkB leads to the activation of downstream signaling molecules, such as phosphoinositide-3 kinase/ protein kinase B (PI3K/Akt) [9-11], which induces the differential regulation of apoptosis and metastasis. However despite the increasing emphasis on TrkB in human tumors, whether it positively participates in primary human NSCLC has not yet been determined. At present, 
little is known about the molecular mechanisms that elicit signalings downstream of TrkB in the progression of NSCLC.

Proline-rich tyrosine kinase 2 (Pyk2) is an extensively expressed non-receptor tyrosine kinase and integrates signals from receptor tyrosine kinases and intracellular signaling molecules in the essential cellular processes such as cell differentiation [12], proliferation [13] and migration [14]. Pyk2 is rapidly tyrosine phosphorylated in response to various extracellular signals $[15,16]$ and activated Pyk2 signaling promotes cell survival and migration in an anchorage-independent manner [17]. The tyrosine 402 (Tyr402) of Pyk2 serves as the primary autophosphorylation site that is essential for Pyk2 activity and function [18], which is supported by the high activity of Tyr402 found in tumor cells with a more invasive and metastatic phenotype $[19,20]$.

This study is designed to investigate the expression and clinical significance of TrkB in 60 cases of surgically resected NSCLC and the potential downstream signaling of TrkB in BDNF-induced invasion of A549 cells. We reported here that high expression of TrkB was common in NSCLC, particularly correlated with lymph node metastasis and TNM stage. We also reported that TrkB-siRNA interrupted BDNF-promoted Pyk2 and extracellular regulating kinase (ERK) activations and invasion of A549 cells. Similarly, Pyk2-siRNA inhibited BDNF-associated ERK phosphorylation and cells invasion. Therefore, TrkB/Pyk2/ ERK signaling was considered to mediate BDNF-induced invasion of A549 cells. These results identify TrkB as a potential novel regulator of cell invasion and the suppression of TrkB may provide a helpful target for inhibitory therapies of metastasis in NSCLC.

\section{Methods NSCLC Samples}

A total of 60 cases of NSCLC were obtained from the Pathology Department of China Medical University. This study was approved by the Medical Research Ethics Committee of China Medical University and the informed consent was obtained from all patients. All of the enrolled patients underwent curative surgical resection without having chemotherapy or radiation therapy. Formalin-fixed paraffin-embedded sections of tumor were stained routinely with hematoxylin and eosin (HE), and reviewed by two senior pathologists in order to determine the histological type and stage, according to the WHO classification of lung and pleural tumors (2004) and the TNM staging system (1997). Lymph node status was determined by routine pathological examination of dissected nodes. Clinicopathological information of the patients about tumor size, histological type, differentiation, stage and lymph node metastasis was obtained from patient records, and summarized in Table 1.

\section{Immunohistochemistry}

60 paraffin sections of NSCLC were deparaffinized and rehydrated routinely. The recovery of antigens was performed by heating the slides in an autoclave sterilizer for $2 \mathrm{~min}$ in $0.1 \mathrm{~mol} / \mathrm{L}$ Tris- $\mathrm{HCl}$ at $\mathrm{pH} 10$. The sections were incubated overnight at $4{ }^{\circ} \mathrm{C}$ with primary rabbit polyclonal antibody detecting TrkB (1:100 dilution, Santa Cruz), following $3 \% \mathrm{H}_{2} \mathrm{O}_{2}$ and $5 \%$ rabbit serum treatment at $37^{\circ} \mathrm{C}$ for $1 \mathrm{~h}$. After which they were incubated with second antibody and streptavidin-peroxidase (SP) complex for $30 \mathrm{~min}$ (SP kit, MaiXin, China), and

Table 1 Clinicopathological characteristics of 60 cases of NSCLC and TrkB expression by immunohistochemistry.

\begin{tabular}{|c|c|c|c|c|}
\hline Clinicopathological charateristics & Cases $(n=60)$ & Higher exression $(n=40)$ & Lower expression $(n=20)$ & $P$ value \\
\hline \multicolumn{5}{|l|}{ Tumor size and invasiveness } \\
\hline $\mathrm{T} 1+\mathrm{T} 2$ & 40 & 27 & 13 & 0.846 \\
\hline $\mathrm{T} 3+\mathrm{T} 4$ & 20 & 13 & 7 & \\
\hline \multicolumn{5}{|l|}{ Histological type } \\
\hline $\mathrm{Sq}$ & 25 & 15 & 10 & 0.355 \\
\hline $\mathrm{Ad}$ & 35 & 25 & 10 & \\
\hline \multicolumn{5}{|l|}{ Differentiation } \\
\hline well-moderate & 44 & 28 & 16 & 0.409 \\
\hline Poor & 16 & 12 & 4 & \\
\hline \multicolumn{5}{|l|}{ Stage } \\
\hline$|+| \mid$ & 34 & 19 & 15 & $0.043^{*}$ \\
\hline III & 26 & 21 & 5 & \\
\hline \multicolumn{5}{|l|}{ Lymph node status } \\
\hline+ & 30 & 24 & 6 & $0.028^{* *}$ \\
\hline- & 30 & 16 & 14 & \\
\hline
\end{tabular}

TrkB expression: ${ }^{*}=$ significant difference between early (I+II) and advanced (III) stage of NSCLCs; ${ }^{* *}=$ significant difference between tumors with positive (+) and negative (-) nodes. 
then visualized with 3,3'-diaminobenzidine (DAB). Neuroblastoma sections were used as positive controls for $\operatorname{TrkB}$, and negative controls were prepared by nonimmune rabbit IgG. All the immunoreactions were separately evaluated by two senior pathologists. Cells with brown particles appearing in cell membrane or cytoplasm was as regarded as TrkB-positive. The intensity of TrkB immunostaining ( 1 = weak, 2 = intense) and the percentage of positive tumor cells $(0 \%=$ negative, $1-50 \%$ $=1,51-75 \%=2, \geq 76 \%=3$ ) were assessed in at least 5 high power fields $(\times 400$ magnification). The scores of each tumorous sample were multiplied to give a final score of $0,1,2,3,4$, or 6 , and the tumors were finally determined as negative: score 0 ; lower expression: score $\leq 3$; or higher expression: score $>3$.

\section{Cells culture and treatments}

Human bronchial epithelial (HBE) and lung adenocarcinoma A549 cells were preserved in our department. HBE cells were grown in RPMI 1640 and A549 cells were cultured in DMEM (Invitrogen) supplemented with $10 \%$ fetal bovine serum (FBS), $100 \mathrm{U} / \mathrm{ml}$ penicillin and streptomycin, in incubator with $5 \% \mathrm{CO}_{2}$ at $37^{\circ} \mathrm{C}$. HBE and A549 cells (80-90\% confluence) were firstly treated with $100 \mathrm{ng} / \mathrm{ml}$ BDNF for $24 \mathrm{~h}$. To knockdown TrkB or Pyk2 for subsequent studies, A549 cells (50$60 \%$ confluence) were transfected with either TrkB- or Pyk2-siRNA and scrambled control siRNA (GeneChem, China) for $48 \mathrm{~h}$ using Lipofectamin2000 (Invitrogen), according to the manufacturer's instructions. Cells were then treated with $100 \mathrm{ng} / \mathrm{ml}$ BDNF at $24 \mathrm{~h}$ after transfection and maintained for another $24 \mathrm{~h}$. Where indicated, the ERK inhibitor (PD98059, Calbiochem) at 100 $\mu \mathrm{mol} / \mathrm{L}$ was added to cells for $48 \mathrm{~h}$. Cells were also treated with $100 \mathrm{ng} / \mathrm{ml} \mathrm{BDNF}$ at $24 \mathrm{~h}$ after PD98059 treatment and maintained throughout the experiments. Those cells treated were used for proteins extraction or cell invasion analysis as described below. The experiments for cells were repeated at least three times.

\section{Cell invasion analysis}

Cell invasion assay was performed using a 24-well Transwell chamber (Costar). At $24 \mathrm{~h}$ following treatments as described above, cells $\left(1 \times 10^{4}\right)$ were detached and seeded in the upper chamber (containing $100 \mathrm{ng} / \mathrm{ml}$ BDNF) with an $8 \mu \mathrm{m}$ pore size insert precoated with Matrigel (BD Biosciences) in the 24-well plate and cultured for another $24 \mathrm{~h}$. Cells were allowed to migrate towards medium containing $15 \%$ FBS in the bottom chamber. The non-migratory cells on the upper membrane surface were removed with a cotton tip, and the migratory cells attached to the lower membrane surface were fixed with $4 \%$ paraformaldehyde and stained with hematoxylin. The number of migrated cells was counted in 5 randomly selected $200 \times$ power fields under microscope. Data expressed are representative of three individual wells.

\section{Western blot}

Cells were washed twice with ice-cold phosphate buffer saline (PBS) and lysed in lysis buffer containing $20 \mathrm{mM}$ Tris- $\mathrm{HCl}, 1 \mathrm{mM}$ EDTA, $50 \mathrm{mM} \mathrm{NaCl}, 50 \mathrm{mM} \mathrm{NaF}, 1$ $\mathrm{mM} \mathrm{Na} \mathrm{VO}_{4}, 1 \%$ Triton-X100, $1 \mathrm{mM}$ phenylmethyl sulfonylfluoride (PMSF) and phosphatase inhibitor. The homogenate was centrifuged at $15000 \mathrm{rpm}$ for $30 \mathrm{~min}$ at $4{ }^{\circ} \mathrm{C}$. The supernatant was extracted and protein content was determined by the BCA (bicinchoninic acid) assay (Pierce). $80 \mu \mathrm{g}$ of total protein was separated by sodium dodecyl sulfate-polyacrylamide gel electrophoresis (SDS-PAGE) and then transferred to polyvinylidene fluoride (PVDF) membrane. After blocking with 5\% bovine serum albumin (BSA), primary antibodies including rabbit polyclonal anti-TrkB, anti-Pyk2, anti-pTyr402, anti- $\beta$-actin, mouse monoclonal anti-p-ERK (all from Santa Cruz) were incubated on the membranes overnight at $4^{\circ} \mathrm{C}$. The membranes were then incubated for $2 \mathrm{~h}$ at $37^{\circ} \mathrm{C}$ with secondary antibodies (ZhongShan, China). Immunoreactive straps were identified using the enhanced chemiluminescence (ECL) system (KeyGEN, China), as directed by the manufacturer. The DNR Imaging System was used to catch up the specific bands, and the optical density of each band was measured using the Image J software. The ratio between the optical density of interest proteins and $\beta$-actin of the same sample was calculated as the relative content of protein detected.

\section{Statistical analysis}

The SPSS 13.0 software was applied to complete data processing. $\chi^{2}$-test was applied to analyze the correlations between TrkB expression and clinicopathological characteristics. T-test or One-way ANOVA was used to compare the differences between cells with various treatments. All data were represented as mean \pm SD and results were considered statistically significant when the p-value was less than 0.05 .

\section{Results}

\section{The Expression of TrkB in 60 NSCLCs by} Immunohistochemistry

TrkB immunoreactivity was detected in 52 (86.7\%) neoplastic sections. We considered that 40 (66.7\%) cases of NSCLC were higher expression (scores of 4 or 6 ) and 20 cases $(33.3 \%)$ were lower expression (scores of $0,1,2$ or 3), as described above in Materials and methods. TrkB has been reported to facilitate tumor metastasis $[21,22]$, and the association between TrkB expression and the presence of lymph node metastasis at the time 
of resection was analyzed statistically. TrkB immunostaining was stronger in NSCLCs with lymph node metastasis compared with those node negative cases and a statistically significant correlation between higher TrkB expression and positive node was found $(\mathrm{P}=$ 0.028). In addition, patients with higher TrkB expression had advanced stage of NSCLC (I+II versus III, P = 0.043). However, no significant difference of TrkB expression was found between tumor size $(\mathrm{T} 1+\mathrm{T} 2$ versus $\mathrm{T} 3+\mathrm{T} 4, \mathrm{P}=0.846$ ), histological type (Ad versus $\mathrm{Sq}$, $\mathrm{P}=0.355$ ) and differentiation (well-moderate versus poor, $\mathrm{P}=0.409)$. Samples of TrkB expression in NSCLCs with and without lymph node metastasis are shown in Figure 1. The correlations of TrkB expression and clinicopathological characteristics are shown in Table 1.

\section{Effect of BDNF on Cell Invasion}

To investigate the potential signaling induced by BDNF that regulates cell invasion, $\mathrm{HBE}$ and A549 cells were used in this study. TrkB expression was examined in HBE and A549 cells and simultaneously, the invasion of these cells treated by BDNF was analyzed by Transwell assay. A549 cells exhibited much higher level of TrkB, which was hardly detectable in HBE cells (Figure 2A). As shown in Figure 2C, the invasive numbers of $\mathrm{HBE}$ and A549 cells with or without BDNF treatment at $24 \mathrm{~h}$ time point were $10.8 \pm 1.4,11.7 \pm 1.9(\mathrm{p}=0.549)$ and $19.5 \pm 3.5,30.7 \pm 5.0(\mathrm{P}=0.033)$, respectively. We also examined the activations of Pyk2 and ERK after BDNF treatments. Pyk2 phosphorylation in Tyr402 was increased in A549 cells upon BDNF stimulation, which was not observed in TrkB-null expressed HBE cells. The activity of ERK was also elevated by BDNF in A549 cells, compared with HBE cells (Figure 2B). These results showed that BDNF promoted the invasion of TrkB-positive A549 cells probably via Pyk2 phosphorylation in Tyr402, and the activations of both Pyk2 and ERK were participated in BDNF-induced invasion of A549 cells.

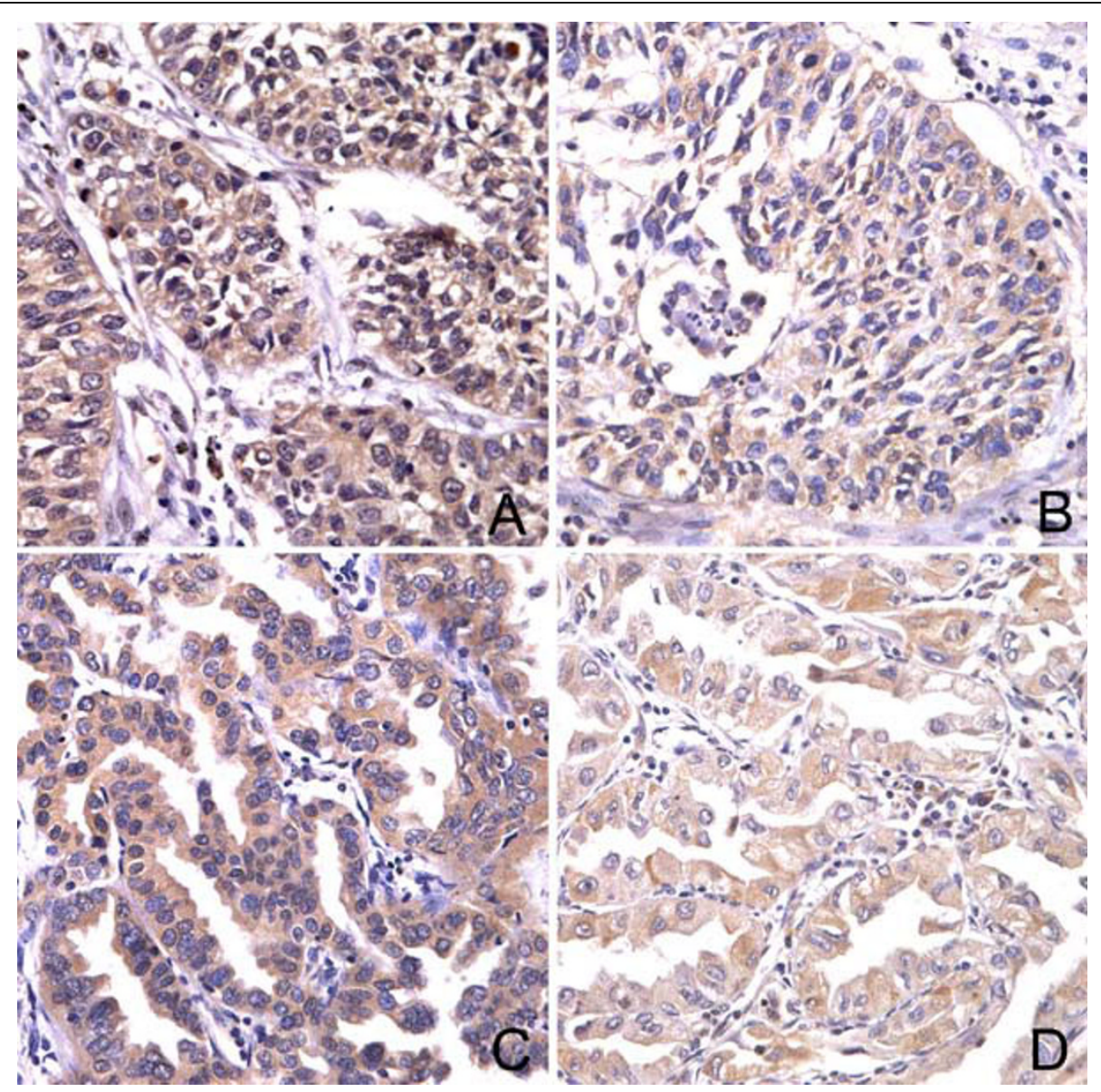

Figure 1 The expression of TrkB in NSCLC examined by immunohistochemistry. TrkB immunostaining in lung squamous cell carcinoma with (A) and without (B) lymph node metastasis. TrkB immunoreactivity in lung adenocarcinoma with (C) and without (D) positive nodes. It was suggested that TrkB expression was correlated with lymph node status. Original magnification, all $\times 400$. 


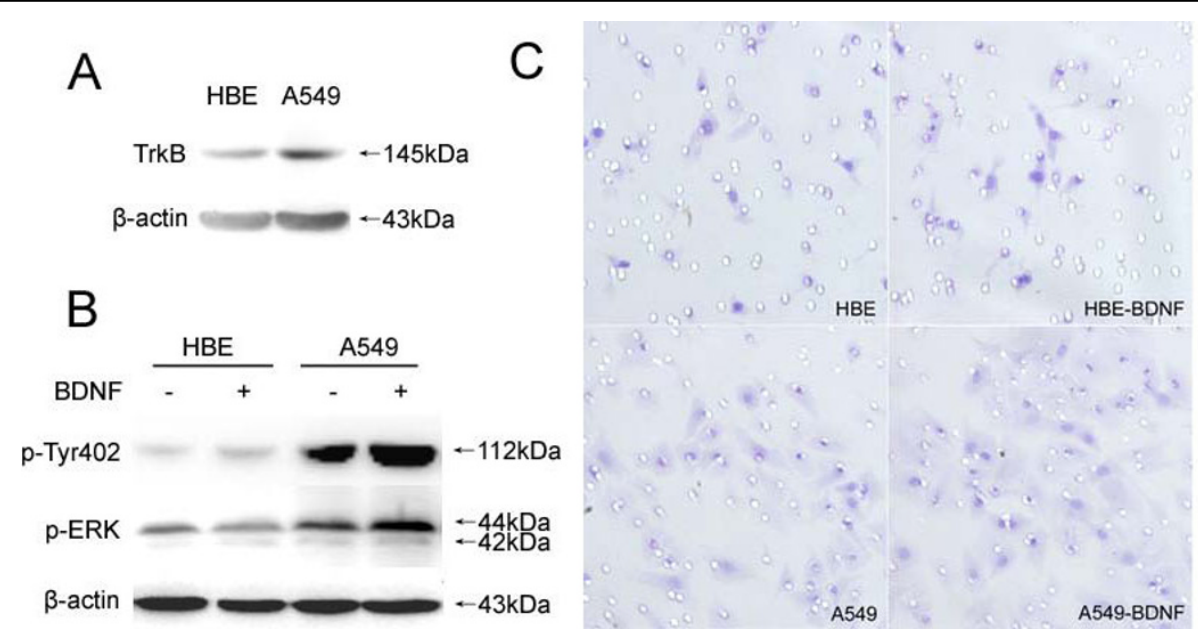

Figure 2 Comparison of TrkB expression in HBE and A549 cells by western blot. HBE cells exhibited a minimal amount of TrkB and much higher level of TrkB was found in A549 cells (A). In the presence of BDNF, the phosphorylations of Pyk2 in Tyr402 and ERK were promoted in TrkB-positive A549 cells, which were not observed in TrkB-null HBE cells (A). Simultaneously, the invasive number of A549 cells was increased after BDNF treatment, while the invasion of HBE cells was not affected (B). Original magnification, all $\times 400$. The experiments for cells were repeated at least three times.

Interruption of BDNF-induced Cell Invasion by TrkB-siRNA To define the role of TrkB in regulating BDNF-stimulated cell invasion, we utilized A549 cells due to the high expression of TrkB and the facilities of culture and transfection. The effects of decreased expression of TrkB on BDNF-induced cell invasion and the activations of Pyk2 and ERK by TrkB-siRNA were examined. Figure 3A showed that in TrkB-siRNA transfected A549 cells, the inhibited TrkB led to the decreased activity of Pyk2 elicited by BDNF, which was detected by the phosphorylation of Tyr402, lower than that in non-silencing siRNA transfected and control cells. The activation of ERK by BDNF was also attenuated after TrkB blocking. The invasive numbers of TrkB-siRNA, non-silencing and control A549 cells were $32.7 \pm 2.8,30.7 \pm 4.3$ and 18.6 \pm 2.2 respectively $(\mathrm{P}=0.003$, Figure $3 \mathrm{~B})$. Therefore, TrkB knockdown cells exhibited reduced Pyk2 and ERK activations and diminished cell invasion.

\section{Effect of Pyk2-siRNA on BDNF-induced Cell Invasion}

Studies have shown that Pyk2 mediated cell invasion [23], and we have observed the activation of Pyk2 by BDNF. We next transiently established Pyk2 knockdown A549 cells by specific siRNA to determine the role of Pyk2 in BDNF-induced cell invasion. Pyk 2 knockdown cells had TrkB expression similar to those non-silencing and control cells, as shown in Figure 4A. However the activation of ERK by BDNF treatment was greatly reduced. In addition, the invasive numbers of Pyk2-siRNA, non-silencing and control A549 cells were 29.4 $\pm 3.8,30.0 \pm 3.0$ and 16.9 \pm 3.2 , respectively $(P=0.005$, Figure $4 B)$. It seems that the inhibited expression of Pyk2 in those cells significantly correlated with decreased ERK activity and suppressed cell invasion induced by BDNF.

\section{Suppression of BDNF-induced Cell Invasion by PD98059}

We further investigated whether the activated ERK was definitely involved in BDNF promoted cell invasion by treating A549 cells with PD98059, a specific inhibitor for ERK. The inhibited phosphorylation of ERK was available by PD98059, as Figure 5A demonstrated. The invasive numbers of PD98059 treated or untreated A549 cells at $24 \mathrm{~h}$ were $27.9 \pm 4.5$ and $18.2 \pm 3.6$, respectively $(\mathrm{P}=0.042$, Figure $5 \mathrm{~B})$. Consequently, in the presence of PD98059, the activation of ERK was diminished concurrently with decreased invasive cells. It seems that the activated ERK played an essential role in regulating the invasion of A549 cells induced by BDNF. Collectively, these data suggested a novel, functional role of BDNF via TrkB in activating Pyk2 and ERK and enhancing the invasion of A549 cells.

\section{Discussion}

The invasion of tumor cells plays a critical role for a successful metastasis. In this study, we investigated a potential signaling that regulates the invasion of A549 cells. Our data suggested a novel signaling by which BDNF facilitates the invasion of A 549 cells via TrkB/ Pyk2/ERK pathway, which possibly contributes to the metastasis of those lung cancer cells. Our study indicated that $\operatorname{TrkB}$ plays a critical role in promoting the invasion of A549 cells, which is mediated by a mechanism closely associated with the activations of Pyk2 and ERK. 


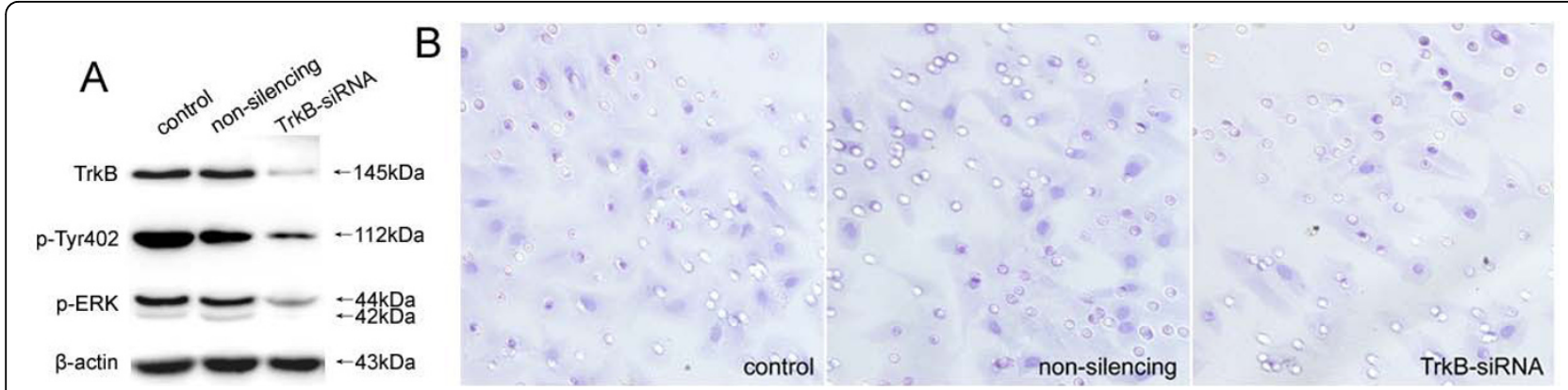

Figure 3 Interruption of BDNF-induced cell invasion by TrkB-siRNA. In TrkB-siRNA transfected A549 cells, the decreased activity of Pyk2 in Tyr402 promoted by BDNF was detected, which was much lower than that in non-silencing siRNA transfected and control cells. The activation of ERK was also attenuated after TrkB silencing (A). The invasion of TrkB-siRNA transfected A549 cells was greatly inhibited, in comparison to those non-silencing and control cells (B). Original magnification, all $\times 400$. The data are representative of three individual experiments.

The expression of TrkB is up-regulated in a variety of human tumors, such as hepatoma, pancreatic ductal adenocarcinoma, Wilms' tumor, astrocytoma and glioblastoma [24-27]. This study evaluated TrkB expression to determine the clinical significance of TrkB for the advanced NSCLC. We examined 60 cases of NSCLC by means of immunohistochemistry and found a statistical evidence of TrkB higher expression in NSCLC, and patients with higher TrkB expression had a significant metastatic phenotype, supporting the potential role of TrkB in survival and metastasis of tumor cells $[28,29]$. Therefore, the higher expression of TrkB probably plays an important role in the progression of NSCLC.

To investigate the potential function in BDNF-induced cell invasion, TrkB expression was compared between HBE and A549 cells. We found that the expression of TrkB in HBE cells was much lower, and A549cells with higher expression of TrkB seemed to be more invasive. Thus, TrkB was considered to be involved in the invasion of A549 cells. Compared with A549 cells, BDNF had no effects on Pyk2 and ERK activations or the invasion of HBE cells, which suggested that in TrkB-positive A549 cells, up-regulated TrkB was readily activated upon BDNF, and signaling pathways initiated by TrkB led to an immediate activation of Pyk2 and Pyk2mediated functions.

Recent studies have been shown that inactivation of Trk by tyrosine kinase inhibitors was correlated with the inhibited invasion of tumor cells [30] and aiming at interfering TrkB expression or activation might be helpful in the progression of effective anticancer therapies. Our TrkB knockdown experiments in this study demonstrated a critical role of TrkB in BDNF-induced Pyk2 and ERK activations and the invasion of A549 cells. Further investigations should be carried out for the detailed activation and interaction between TrkB and Pyk2 in other lung cancer cell lines or in vivo.

The involvement of Pyk2 in the invasion of TrkB-positive A549 cells was clearly evident that the phosphorylation in Tyr402 was up-regulated by BDNF as well as cell invasion. Since BDNF-induced cell invasion was significantly reduced in Pyk2 knockdown cells, it was indicated that Pyk2 was required for regulating the invasion of A549 cells. Pyk2-mediated functions were performed by activating multiple downstream signaling molecules, including ERK, p38, c-Src and paxillin, which led to the

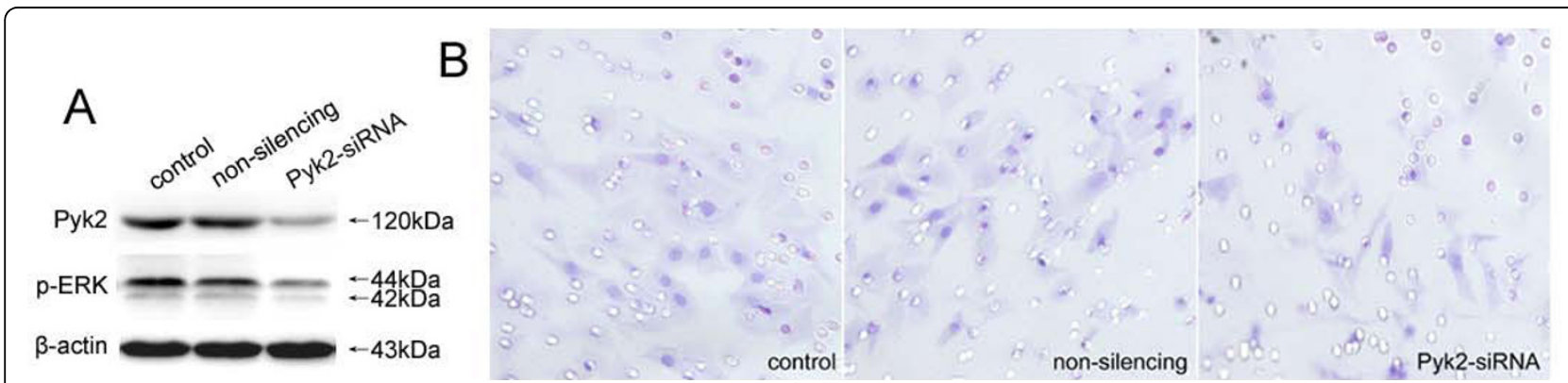

Figure 4 Effects of Pyk2-siRNA on BDNF-induced cell invasion. Pyk2 knockdown cells had TrkB expression unaffected, while the activation of ERK promoted by BDNF treatment was largely reduced (A). In addition, the invasive number of Pyk2-siRNA transfected A549 cells was significantly decreased and less than those non-silencing and control cells (B). Original magnification, all $\times 400$. The data are representative of three replicates. 


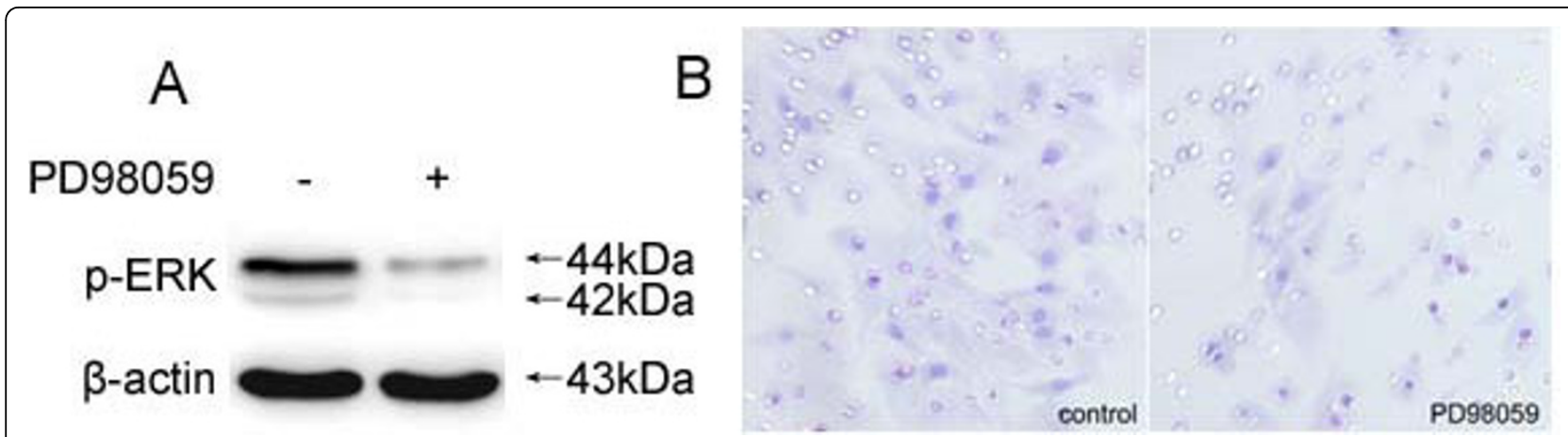

Figure 5 Suppression of BDNF-induced cell invasion by PD98059. The inhibited phosphorylation of ERK was observed after PD98059 treatment (A). The invasion of PD98059 treated A549 cells was diminished accordingly, compared with those non-silencing and control cells (B). It was indicated that the activated ERK was essential for regulating the invasion of A549 cells induced by BDNF. Original magnification, all $\times 400$. The results are representative of three independent experiments.

differential regulation of cell invasion in various cell types [31-34]. The activation of ERK was observed after BDNF treatment, which was inhibited by Pyk2-siRNA and concomitant with a decreased cell invasion. Thus, we considered that ERK activated by Pyk2 was participated in the invasion of A549 cells stimulated by BDNF. Further experiments are necessary to clarify if other signaling molecules are involved in BDNF-induced cell invasion.

Taken together, our study confirmed that TrkB was overexpressed in NSCLCs. When activated by BDNF, TrkB induced Pyk2 phosphorylation in Tyr402, which led to ERK activation and promoted cell invasion. Our data thus revealed a TrkB/Pyk2/ERK signaling pathway that regulated the invasion of A549 cells and provided potential targets for the metastasis of NSCLC. Nevertheless, other signaling pathway(s) involved in the TrkBassociated invasion of lung cancer cells required further studies.

\section{Conclusions}

Our data suggested that TrkB was higher expressed in NSCLC and patients with more TrkB expression had significant metastatic lymph nodes. In A549 cells, when activated by BDNF, TrkB mediated Pyk2 phosphorylation in Tyr402, led to ERK activation and promoted cell invasion. Our data thus revealed the involvement of TrkB in lymph node metastasis of NSCLC and a TrkB/ Pyk2/ERK signaling pathway that regulated the invasion of A549 cells and provided potential targets for the metastasis of NSCLC.

\section{Acknowledgements}

The authors declare that they have no conflict of interest. We are grateful to teacher Wei Wang, Yan Wang, Lei Zhao, Jian Gao, Lu Yao, Mo Zhou for technical assistance and experimental instructions, and the members of our department for useful suggestions.

\section{Author details}

${ }^{1}$ Center of Laboratory Technology and Experimental Medicine, China Medical University, Shenyang, China. ${ }^{2}$ Department of General Surgery, the Fourth Affiliated Hospital of China Medical University, Shenyang, China.

${ }^{3}$ Department of Pathology, the First Affiliated Hospital and College of Basic Medical Sciences of China Medical University, Shenyang, China.

\section{Authors' contributions}

SZ initiated the research, carried out the experiments and wrote the manuscript, DG contributed to the paper translation, WL and QZ gave experimental instructions, $Y Z, C L$ and $Y L$ helped with the experimental design, $Z C$ and $X Q$ gave funding support and critical review of the manuscript. All authors read and approved the final manuscript.

\section{Competing interests}

The authors declare that they have no competing interests.

Received: 25 September 2009

Accepted: 16 February 2010 Published: 16 February 2010

\section{References}

1. Schramm A, Schulte JH, Astrahantseff K, Apostolov O, Limpt V, Sieverts H, Kuhfittig-Kulle S, Pfeiffer P, Versteeg R, Eggert A: Biological effects of TrkA and TrkB receptor signaling in neuroblastoma. Cancer Lett 2005, 228:143-53.

2. Jaboin J, Hong A, Kim CJ, Thiele CJ: Cisplatin-induced cytotoxicity is blocked by brain-derived neurotrophic factor activation of TrkB signal transduction path in neuroblastoma. Cancer Lett 2003, 193:109-14.

3. Hecht $M$, Schulte JH, Eggert A, Wilting J, Schweigerer L: The neurotrophin receptor TrkB cooperates with c-Met in enhancing neuroblastoma invasiveness. Carcinogenesis 2005, 26:2105-2115.

4. Matsumoto K, Wada RK, Yamashiro JM, Kaplan DR, Thiele CJ: Expression of brain-derived neurotrophic factor and pl4STrkB affects survival, differentiation, and invasiveness of human neuroblastoma cells. Cancer Res 1995, 55:1798-1806.

5. Yu X, Liu L, Cai B, He Y, Wan X: Suppression of anoikis by the neurotrophic receptor TrkB in human ovarian cancer. Cancer Sci 2008, 99:543-52.

6. Zhang Y, Fujiwara Y, Doki Y, Takiguchi S, Yasuda T, Miyata H, Yamazaki M, Ngan CY, Yamamoto H, Ma Q, Monden M: Overexpression of tyrosine kinase B protein as a predictor for distant metastases and prognosis in gastric carcinoma. Oncology 2008, 75:17-26.

7. Sclabas GM, Fujioka S, Schmidt C, Li Z, Frederick WA, Yang W, Yokoi K, Evans DB, Abbruzzese JL, Hess KR, Zhang W, Fidler IJ, Chiao PJ: Overexpression of tropomysin-related kinase B in metastatic human pancreatic cancer cells. Clin Cancer Res 2005, 11:440-9.

8. Douma S, Van Laar T, Zevenhoven J, Meuwissen R, Van Garderen E, Peeper DS: Suppression of anoikis and induction of metastasis by the neurotrophic receptor TrkB. Nature 2004, 430:1034-9. 
9. Jaboin J, Kim CJ, Kaplan DR, Thiele CJ: Brain-derived neurotrophic factor activation of TrkB protects neuroblastoma cells from chemotherapyinduced apoptosis via phosphatidylinositol 3-kinase pathway. Cancer Res 2002, 62:6756-6763.

10. Li Z, Jaboin J, Dennis PA, Thiele CJ: Genetic and pharmacologic identification of Akt as a mediator of brain-derived neurotrophic factor/ TrkB rescue of neuroblastoma cells from chemotherapy-induced cell death. Cancer Res 2005, 65:2070-5.

11. Li Z, Thiele CJ: Targeting Akt to increase the sensitivity of neuroblastoma to chemotherapy:lessons learned from the brain-derived neurotrophic factor/TrkB signal transduction pathway. Expert Opin Ther Targets 2007, 11:1611-21.

12. Schindler EM, Baumgartner M, Gribben EM, Li L, Efimova T: The role of proline-rich protein tyrosine kinase 2 in differentiation-dependent signaling in human epidermal keratinocytes. J Invest Dermatol 2007, 127:1094-106.

13. Picascia A, Stanzione R, Chieffi P, Kisslinger A, Dikic I, Tramontano D: Proline-rich tyrosine kinase 2 regulates proliferation and differentiation of prostate cells. Mol Cell Endocrinol 2002, 186:81-7.

14. Kuwabara K, Nakaoka T, Sato K, Nishishita T, Sasaki T, Yamashita N: Differential regulation of cell migration and proliferation through proline-rich tyrosine kinase 2 in endothelial cells. Endocrinology 2004, 145:3324-30.

15. Massa A, Casagrande S, Bajetto A, Porcile C, Barbieri F, Thellung S, Arena S, Pattarozzi A, Gatti M, Corsaro A, Robello M, Schettini G, Florio T: SDF-1 controls pituitary cell proliferation through the activation of ERK1/2 and the Ca2+-dependent, cytosolic tyrosine kinase PYK2. Ann N Y Acad Sc 2006, 1090:385-98.

16. Rocic P, Govindarajan G, Sabri A, Lucchesi PA: A role for PYK2 in regulation of ERK1/2 MAP kinases and PI3-kinase by ANG II in vascular smooth muscle. Am J Physiol Cell Physiol 2001, 280:C90-9.

17. Wei L, Yang Y, Zhang X, Yu Q: Altered regulation of Src upon cell detachment protects human lung adenocarcinoma cells from anoikis. Oncogene 2004, 23:9052-61.

18. Park SY, Li H, Avraham S: RAFTK/PYK2 regulates EGF-induced PC12 cell spreading and movement. Cell Signal 2007, 19:289-300.

19. Zrihan-Licht S, Fu Y, Settleman J, Schinkmann K, Shaw L, Keydar I, Avraham S, Avraham H: RAFTK/PYK2 tyrosine kinase mediates the association of $\mathrm{p} 190$ RhoGAP with RasGAP and is involved in breast cancer cell invasion. Oncogene 2000, 19:1318-28.

20. Zhang S, Qiu X, Gu Y, Wang E: Up-regulation of proline-rich tyrosine kinase 2 in non-small cell lung cancer. Lung Cancer 2008, 62:295-301.

21. Geiger TR, Peeper DS: Critical role for TrkB kinase function in anoikis suppression, tumorigenesis, and metastasis. Cancer Res 2007, 67:6221-9.

22. Walch ET, Marchetti D: Role of neurotrophins and neurotrophins receptors in the in vitro invasion and heparanase production of human prostate cancer cells. Clin Exp Metastasis 1999, 17:307-14.

23. Lipinski CA, Tran NL, Menashi E, Rohl C, Kloss J, Bay RC, Berens ME, Loftus JC: The tyrosine kinase PYK2 promotes migration and invasion of glioma cells. Neoplasia 2005, 7:435-45.

24. Zhang Z, Han L, Liu Y, Liang X, Sun W: Up-regulation of Tropomyosin related kinase $B$ contributes to resistance to detachment-induced apoptosis in hepatoma multicellular aggregations. Mol Biol Rep 2009, 36:1211-6

25. Miknyoczki SJ, Lang D, Huang L, Klein-Szanto AJ, Dionne CA, Ruggeri BA: Neurotrophins and Trk receptors in human pancreatic ductal adenocarcinoma: expression patterns and effects on in vitro invasive behavior. Int J Cancer 1999, 81:417-427.

26. Eggert A, Grotzer MA, Ikegaki N, Zhao H, Cnaan A, Brodeur GM, Evans AE: Expression of the neurotrophin receptor TrkB is associated with unfavorable outcome in Wilms' tumor. J Clin Oncol 2001, 19:689-896.

27. Wadhwa S, Nag TC, Jindal A, Kushwaha R, Mahapatra AK, Sarkar C Expression of the neurotrophin receptors Trk A and Trk B in adult human astrocytoma and glioblastoma. J Biosci 2003, 28:181-8.

28. Rubin JB, Segal RA: Growth, survival and migration: the Trk to cancer. Cancer Treat Res 2003, 115:1-18.

29. Pearse RN, Swendeman SL, Li Y, Rafii D, Hempstead BL: A neurotrophin axis in myeloma: TrkB and BDNF promote tumor-cell survival. Blood 2005, 105:4429-36.

30. Festuccia C, Muzi P, Gravina GL, Millimaggi D, Speca S, Dolo V, Ricevuto E, Vicentini C, Bologna M: Tyrosine kinase inhibitor CEP-701 blocks the
NTRK1/NGF receptor and limits the invasive capability of prostate cancer cells in vitro. Int J Oncol 2007, 30:193-200.

31. Sun CK, Man K, Ng KT, Ho JW, Lim ZX, Cheng Q, Lo CM, Poon RT, Fan ST: Proline-rich tyrosine kinase 2 (Pyk2) promotes proliferation and invasiveness of hepatocellular carcinoma cells through c-Src/ERK activation. Carcinogenesis 2008, 29:2096-105.

32. McMullen M, Keller R, Sussman M, Pumiglia K: Vascular endothelial growth factor-mediated activation of p38 is dependent upon Src and RAFTK/ Pyk2. Oncogene 2004, 23:1275-82.

33. Park SY, Avraham HK, Avraham S: RAFTK/Pyk2 activation is mediated by trans-acting autophosphorylation in a Src-independent manner. J Biol Chem 2004, 279:33315-22.

34. Ohanian V, Gatfield K, Ohanian J: Role of the actin cytoskeleton in Gprotein-coupled receptor activation of PYK2 and paxillin in vascular smooth muscle. Hypertension 2005, 46:93-9.

\section{Pre-publication history}

The pre-publication history for this paper can be accessed here:http://www. biomedcentral.com/1471-2407/10/43/prepub

doi:10.1186/1471-2407-10-43

Cite this article as: Zhang et al:: TrkB is highly expressed in NSCLC and mediates BDNF-induced the activation of Pyk2 signaling and the invasion of A549 cells. BMC Cancer 2010 10:43.

\section{Submit your next manuscript to BioMed Central and take full advantage of:}

- Convenient online submission

- Thorough peer review

- No space constraints or color figure charges

- Immediate publication on acceptance

- Inclusion in PubMed, CAS, Scopus and Google Scholar

- Research which is freely available for redistribution

Submit your manuscript at www.biomedcentral.com/submit
C) Biomed Central 